\title{
No caminho da formação docente em música: descobrindo saídas, criando estratégias, tornando-me professora
}

Nicole Penteado

Recebido em 04/06/2018

Aprovado em 06/09/2018 
Este trabalho buscou discutir meu processo de formação inicial como educadora musical, a partir de minha atuação no Estágio Supervisionado em música. A escolha pela temática se deu em decorrência da significativa presença de registros e reflexões presentes nos relatórios de aula do estágio a respeito de meu desenvolvimento acadêmico e pedagógico, bem como em função de minha história de vida pregressa. Sendo assim, selecionei alguns aspectos que se mostraram relevantes em minha formação, para discutir no trabalho. Para isso, lancei mão do referencial teórico-metodológico Memorial de Formação (SARTORI, 2011; SEVERINO, 1997; PRADO e SOLIGO, 2005). Os resultados dessa reflexão indicam que a escrita reflexiva possibilitou narrar experiências, revelar ideias e refletir sobre minha formação docente, incorporando uma postura reflexiva em minha prática como educadora musical.

Palavras-chave: memorial de formação, formação docente inicial, música na educação infantil.

\section{INTRODUÇÃO}

Neste texto analiso meu processo de formação inicial como educadora musical no curso de Licenciatura em Educação Musical de uma universidade pública, a partir da atuação no Estágio Supervisionado em música, realizado ao longo de 2015, em um Centro Municipal de Educação Infantil (CMEI). Assim, desenvolvo uma reflexão sobre meu desenvolvimento acadêmico e pedagógico.

As reflexões que desenvolvi sobre minha atuação foram feitas a partir dos relatórios de estágio. Estes possibilitaramme uma ampla visão de todo o estágio e de meu processo enquanto estagiária em música na Educação Infantil. Sendo assim, selecionei alguns aspectos, que se mostraram relevantes em minha formação, para discutir neste trabalho. Dentre eles, destaco a forma como fui aprendendo a conhecer e a lidar com as crianças pequenas, com sua forma de fazer 
música e a forma como fui me tornando uma educadora musical, abordando a gestão de sala de aula, as inseguranças decorrentes do processo e as conquistas.

Para isso, lancei mão do referencial teórico-metodológico Memorial de Formação (SARTORI, 2011; SEVERINO, 1997; PRADO e SOLIGO, 2005), um gênero textual que possibilita a narração, por escrito, de histórias e experiências relacionadas à formação acadêmica.

É importante dizer que minha identificação com o tema desse trabalho se deu por conta de minha história de vida pregressa - o fato de gostar de escrever narração, falando sobre mim e organizando ideias; a minha personalidade etc. -, que se entrelaçava com o tema, casando-se ambos. Descobri mais tarde, que, como afirma Mills (2009), a produção acadêmica está estreitamente ligada com a vida pessoal.

Como disse Jerome Bruner (2001), provavelmente, a forma mais natural e imediata de se organizar experiências e conhecimentos próprios é a forma narrativa. Assim, a possibilidade de desenvolver esse trabalho sobre minha formação docente mostrou-se oportuna e coerente com uma prática que tenho exercido ao longo de minha vida.

Quanto ao interesse em desenvolver meu estágio na Educação Infantil, este nasceu quando comecei a observar como havia poucos profissionais, nas escolas específicas de música da cidade $X$ e em outros espaços, que atuavam com essa faixa etária. Diante disso, interessei-me pela área e ingressei como monitora em um curso intitulado Fazendo Música Com Bebês que foi oferecido em 2014 no Departamento de Música (DMU) da referida universidade.

A experiência com o curso contribuiu para meu interesse e vontade em investir nessa temática. Além disso, a partir do ano de 2015 comecei a trabalhar com o ensino de música para bebês e crianças de até 4 anos de idade, numa escola específica de música. Dessa forma, optei pelo estágio com bebês e crianças pequenas e pela pesquisa sobre o trabalho com música a partir desse.

Este texto está organizado em cinco partes, além dessa introdução. Trago inicialmente alguns autores que tratam de assuntos que se relacionam com o tema deste trabalho, 
incluindo Sudan (2005), Santos (2009), Mills (2009) e Louro, Teixeira e Rapôso (2014). Em seguida, falo a respeito da proposta de estágio no $\mathrm{CMEl}$, escola em que se deu a experiência de estágio. Apresento, então, o referencial teórico-metodológico da pesquisa, o Memorial de Formação. O capítulo 5 constitui a parte central do trabalho e apresenta subcapítulos, nos quais abordo diferentes assuntos, todos relacionados ao meu desenvolvimento, bem como dos alunos e do estágio. Por fim, retomo o objetivo do trabalho, sintetizando as análises e discussões realizadas, bem como as considerações e reflexões resultantes. Dessa forma, identifico as contribuições da pesquisa para área da Educação Musical e os ganhos individuais.

Neste trabalho buscou-se preservar a identidade das professoras e auxiliares de Educação Infantil do CMEI. Sendo assim, faço uso de pseudônimos que foram escolhidos por mim. Os nomes das demais estagiárias são verdadeiros.

\section{O QUE DIZEM OUTROS AUTORES}

Alguns autores, de diferentes áreas do conhecimento, têm discutido a própria prática a partir de uma postura reflexiva. Dentre eles, Sudan (2005), da área da Biologia, realizou um estudo autobiográfico inserido numa perspectiva de formação continuada do professor pela prática reflexiva, a partir do qual buscou identificar e analisar seus saberes e as contribuições de certos interlocutores vinculados ao universo escolar ou universitário, promovendo processos reflexivos.

Em outro trabalho, Santos (2009) - professora da área da matemática - investigou um material de autoanálise, denominado Portfólio de Aprendizagens. A autora concluiu, a partir de observação da narração de "professoras-alunas", "que alguns 'eus' professoras são moldados a partir do dispositivo pedagógico do Portfólio de Aprendizagens, quais sejam: 'eureflexivo', 'eu crítico-construtivista e 'eu interdisciplinar'" (SANTOS, 2009, p. 8). A autora explica, ainda, como entrelaçam- 
se sua trajetória de vida e a temática de sua pesquisa, assim como discute Mills (2009).

Na área da Educação Musical, Louro, Teixeira e Rapôso (2014) abordam o assunto da narrativa, em uma perspectiva autobiográfica, a partir de seu grupo de pesquisa intitulado Auto-Narrativas de Práticas Musicais (NarraMus), que busca "estudar fenômenos relacionados a aprender e ensinar música a partir da 'narrativa de si', seja esta analisada a partir de entrevistas ou de diários de bordo" (p. 27).

Neste artigo há um esforço para que a autenticidade de meu próprio desenvolvimento como educadora musical fique traduzida em palavras. Nesse sentido, a legitimidade do texto tem fundamentos no processo formativo e pode contribuir para que outros estudantes em formação inicial se beneficiem.

Para Prado e Soligo (2005) a escrita dos educadores deve ser "valorizada como uma produção legítima, que veicula os saberes produzidos no exercício da profissão e que, por isso, merece ser publicada, divulgada, tomada como subsídio para outros profissionais" (PRADO; SOLIGO, 2005, p. 1). Na mesma direção, Marques (2004), ao tratar da importância do compartilhamento da experiência para o saber, no que diz respeito ao professor, explica:

Conversar sobre as próprias experiências de vida e sobre seus prévios saberes é realizar a interlocução de saberes, dos quais faz a educação, é aprender enquanto reconstrução dos saberes anteriores, é imprimir, assim, vida nova e novos significados de face aos dinamismos da sociedade e da cultura, à ampliação dos horizontes que se abrem como desafios ao entendimento compartilhado e à ação solidária de todas nas comunidades em que vivem e trabalham (MARQUES, 2004, p. 81).

Trata-se de compartilhar conhecimentos, contribuindo para a área da educação, pois "são essas relações intercomplementares do ouvir e do falar que fazem a educação" (MARQUES, 2004, p. 83). Ao falar de compromissos, interesses, modos de pensar e da própria experiência, os professores estão constituindo uma comunidade científica responsável pelos próprios saberes, pelos saberes da profissão docente. 


\section{UM POUCO SOBRE O ESTÁGIO NO CMEI, ONDE A TRILHA SE FEZ}

O CMEl atende crianças de 0 a 5 anos de idade, em período integral, contando com as seguintes turmas: Infantil ${ }^{1}$ I, Infantil II, Infantil III, Infantil IV, Infantil V - A e Infantil V - B. Destas turmas, atuei no Infantil I e no Infantil III. As demais turmas também receberam aulas de música, sendo atendidas por outras estagiárias, também alunas do Departamento de Música da universidade. No estágio estive junto das duas estagiárias em sala de aula e, a partir do segundo semestre, de uma delas, apenas. Cada uma de nós era responsável por duas turmas:

- Nicole - Educação Infantil I e III

- Maressa - Educação Infantil II e IV

- Bruna - Educação Infantil V-A e V-B

Nós entrávamos juntas em sala de aula, sendo que, enquanto uma atuava como professora da turma, as demais atuavam como suas auxiliares. Tratava-se, portanto, de um trabalho colaborativo entre nós, enquanto professoras e estagiárias.

No primeiro semestre o estágio foi realizado uma vez por semana. A partir do segundo semestre, para fechar a cargahorária exigida, fomos duas vezes na semana. Dessa forma, às segundas-feiras Maressa atuava como professora no Infantil III e eu como sua auxiliar, e às sextas-feiras eu dava aula, tendo-a como minha auxiliar.

Além disso, continuei com o Infantil I e Maressa com o Infantil II, sendo que sempre entrávamos juntas nas turmas. Sendo assim, durante o primeiro semestre de 2015 as aulas de música foram realizadas no período da manhã, às segundasfeiras, com duração de 30 minutos hora/aula e no segundo semestre, às segundas e sextas-feiras, e aconteceram de março a novembro do referido ano.

\footnotetext{
${ }^{1}$ A Educação Infantil está organizada em turmas que são denominadas Educação Infantil I, II, III, IV e V, porém, essas turmas são comumente chamadas apenas de "Infantil", terminologia que adoto também neste trabalho.
} 


\section{FUNDAMENTANDO O TRAJETO: O MEMORIAL DE FORMAÇÃO}

Para anotar lembranças ou registrar aquilo que se faz importante para nós, utilizamos a linguagem escrita. Dessa forma, narramos coisas lembradas, acontecimentos passados e refletimos sobre nossa vida, compreendendo nossa própria história. Nessa direção, ao narrar experiências, revelamos ideias e, ao mesmo tempo, refletimos sobre nossas próprias ações.

Segundo Prado e Soligo (2005), o memorial consiste, assim como toda narrativa autobiográfica, em um texto no qual o autor relata a própria vida, buscando narrar aquilo que julga ser, dentre o que vivenciou, mais importante e interessante para si e para seus ouvintes e leitores. É, portanto, "um texto que relata fatos memoráveis, importantes para aquele que o produz, tendo em conta suas memórias" (PRADO; SOLIGO, 2005, p. 6).

A narrativa é feita a partir de memórias, ou seja, só é possível se fizermos uma visita ao passado, a qual nos permite compreender o presente. Nesse sentido, o Memorial de Formação é um gênero textual que possibilita a narração de histórias e experiências, por escrito, preservando-as do esquecimento.

Severino (1997) entende o Memorial enquanto narrativa autobiográfica que envolve a história do narrador e que é histórica e reflexiva, simultaneamente, constituindo um relato histórico, analítico e crítico que trata de fatos que fizeram parte da trajetória acadêmica de seu autor. Na mesma direção, para Prado e Soligo (2005) esse constitui

Um gênero textual predominantemente narrativo, circunstanciado e analítico, que trata do processo de formação num determinado período - combina elementos de textos narrativos com elementos de textos expositivos (os que apresentam conceitos e ideias, a que geralmente chamamos 'textos teóricos'). Se tomarmos em conta a definição mais clássica dos tipos de discurso, - narrativo, descritivo e argumentativo poderíamos dizer então que o memorial de formação é um gênero que comporta todos eles, embora evidentemente predomine o discurso narrativo. Em se 
tratando do estilo, também há lugar para diferentes possibilidades: a opção pode ser por um tratamento mais literário, ou mais reflexivo, ou pela combinação de ambos (PRADO; SOLIGO, 2005, p. 7).

O Memorial de Formação constitui, assim, "um gênero textual privilegiado para que os educadores - enfrentando o desafio de assumir a palavra e tornar públicas as suas opiniões, as suas inquietações, as suas experiências e as suas memórias - escrevam sobre o processo de formação e a prática profissional" (PRADO; SOLIGO, 2005, p. 2). Os autores explicam que o memorial é autocrítico daquele que narra, uma vez que envolve confissões, apresenta paixões, emoções e sentimentos que estão cravados em sua memória.

Nesse sentido, exige que o sujeito fale sobre si próprio, retratando com segurança e fidelidade sua trajetória real que, certamente, é tecida de altos e baixos e de conquistas e perdas, afinal "relatada com autenticidade e criticamente assumida, nossa história de vida é nossa melhor referência" (SEVERINO, 1997, p. 143). Sobre falar da própria prática, Sartori (2011) explica

Exige expor-se, mostrar-se ao outro. Falar sobre a prática pedagógica é também falar de si mesmo. Narrar o que acontece é mostrar ao outro as próprias convicções, os acertos, os erros. Não é tarefa fácil escrever sobre a prática pedagógica porque, ao fazer isso, as contradições entre o que se pensa e o que se faz podem deixar à mostra o sujeito-autor. $\mathrm{E}$ o outro $\mathrm{a}$ quem se escreve, no caso das professoras-alunas que produzem um memorial de formação para um docente de uma instituição de ensino superior, é alguém que pode julgar/avaliar o que é dito e o que é feito (SARTORI, 2011, p. 280).

Sartori (2011) baseia-se em Carrilho et al. (1997) para explicar que o memorial de formação deve constituir-se de reflexões sobre as áreas formativa e profissional, "em cujo texto o autor deverá demonstrar a habilidade de articular as experiências de sua prática pedagógica (profissionais ou referentes ao período do estágio curricular) às suas experiências de formação (...)" (SARTORI, 2011, p. 270). 
O Memorial de Formação tem sido utilizado por educadores, protagonistas de suas ações e de seu processo de formação (SUDAN, 2005; SANTOS, 2009). No meio acadêmico, através dos relatórios de estágio, por exemplo, professores em formação e em exercício utilizam-se dessa ferramenta, articulando teoria e prática e produzindo conhecimentos formativos e pedagógicos. A escrita reflexiva favorece ganhos individuais, além da possibilidade de compartilhamento.

Segundo Sartori (2011)

O memorial de formação tem relevância na formação de professores por propiciar ao sujeito a oportunidade de fundar novos sentidos para experiências pessoais/profissionais (...). Assim, o memorial de formação é um importante instrumento na formação de professores, porque mais do que o registro de um processo reflexivo é o registro de reavaliações de um percurso experienciado (SARTORI, 2011, p. 280).

Escrever reflexivamente significa dar forma a ideias e pensamentos, organizando-os e, assim, compreendendose. Através da autorreflexão é possível combinar percepções de si próprio e de um mundo externo e dar sentido à prática profissional e à vida. Além disso, tem-se a oportunidade de se desenvolver, uma vez que é feita análise de ações próprias.

\section{TORNANDO-ME UMA EDUCADORA MUSICAL}

\section{"A AULA DE MÚSICA PRECISA FLUIR SEM BURACOS"}

No início do trabalho "ligar" uma atividade à outra era uma tarefa difícil. Isso acontecia porque, enquanto eu ia buscar materiais que ficavam sobre o balcão da sala de aula ou me preocupava em olhar o planejamento, por exemplo, certificando-me do que deveria fazer, ausentava-me e deixava as outras duas estagiárias e os alunos, sem dizer nada. Acontecia, principalmente, no Infantil I.

Para quem já teve a oportunidade de assistir em vídeo a uma aula de Betty Jo para crianças, é possível perceber que a 
professora de música não permite longos "espaços" entre as atividades propostas, o que evita que os alunos fiquem dispersos, perdendo a atenção. Sobre isso, Russel (2005) comenta:

Até então, não houve nenhum momento de "águas paradas", isto é, momentos em que as crianças ficaram imóveis e que pudessem ficar distraídas ou perder o interesse. A intensidade com a qual Betty Jo se concentra em cada atividade, a vivacidade com a qual passa de uma atividade à outra, sua escolha de material introdutório e as demandas que fez mostraram às crianças a necessidade de prestarem atenção caso quisessem fazer parte do grupo de músicos (RUSSELL, 2005, p. 74).

Pude perceber tais falhas ouvindo os áudios das aulas, já que gravava todas para fazer os relatórios da forma mais detalhada possível. Além disso, uma vez que a orientadora me acompanhava no trabalho, ela pôde chamar minha atenção para esse aspecto. Passei, então, a falar mais durante a aula, comunicando-me com os bebês e com minhas colegas de estágio. Distribuía entre elas pequenas tarefas, de forma que não ficassem sem ação.

(...) ouvindo o áudio para escrever este relatório percebo como a aula fica cheia de "buracos", porque eu falo muito pouco. Notei, escrevendo este relatório para o Infantil I, que eu começo as atividades "do nada", sem avisar às meninas, sem conversar com os alunos e a aula até fica sem alegria. Sei que isso também tem a ver com o fato de uma das professoras me intimidar com seu comportamento, fazendo com que eu fique "travada", mas vou trabalhar nisso, na minha segurança e confiança, e fazer com que o que ela pensa ou faz não me atinja e não prejudique a aula (Diário de Campo, 2015, Aula 8, Infantil I).

Passei, também, a buscar por atividades que se relacionassem de alguma forma, sempre em prol de eliminar os referidos "buracos". Russell (2005) atribui uma boa gestão de sala de aula a diversos fatores, incluindo a coerência entre as atividades e o movimento: "a escolha de materiais e tarefas e o planejamento para obter coerência e seqüência lógica, usando uma variedade de configurações e movendo-se, sem 
atrasos, de atividade em atividade e de tarefa em tarefa" (RUSSEL, 2005, p. 86).

Pensando assim, para os bebês, minhas atividades enfocavam um dos sentidos (tato, audição, visão) e para os alunos do Infantil III tinham um tema, como, por exemplo, trânsito, animais etc.

Para as próximas aulas vou estudar formas de "ligar" uma atividade à outra, para que tudo fique mais linear. Farei isso pensando em atividades que enfoquem, todas, um dos sentidos a serem desenvolvidos nos bebês: audição, tato e visão (Diário de Campo, 2015, Aula 5, Infantil I).

Esse problema, como trago no trecho de relatório acima, acontecia principalmente por conta de minha insegurança na aula: eu não estava segura quanto ao planejamento; não tinha intimidade com os alunos; enfrentava problemas de relacionamento com algumas professoras do CMEI e a escola ainda não era familiar para mim.

Sendo assim, uma vez que tudo ainda era novo, lidar com os anseios, com a falta de experiência com bebês e crianças pequenas, com o trabalho em grupo, com a ansiedade e com a prática de ser professora, eram tarefas que eu estava aprendendo, o que acontecia através de erros, acertos, observações, reflexões e contribuições de outras pessoas.

Tudo foi sendo solucionado conforme as aulas iam acontecendo, através de meu desenvolvimento, que se dava com a experiência, as orientações, as leituras e a busca por melhorar as aulas.

\section{PLANEJANDO E "REPLANEJANDO": FLEXIBILIDADE E RAPIDEZ EM SALA DE AULA}

O planejamento é uma ação da prática pedagógica que se faz presente no cotidiano do professor. A partir dele, tem-se esquematizada uma série de ações que servem de guia para a realização de atividades e para o desenvolvimento da aula. Nesse sentido, Hentschke e Del Ben (2003) trazem Gimeno Sacristán para explicar que "planejar é antecipar ou representar algo 
que virá a ser realizado; é prever uma ação antes de realizá-la" (HENTSCHKE; DEL BEN, 2003, p. 176).

Não se prender ao planejamento é algo que se aprende com a prática. Inicialmente, é preciso um planejamento bem estruturado, com "segundos planos", para que o professor em formação inicial, ou ainda sem prática de lecionar, sinta-se encorajado a dar aula e amparado, confiante. Mais tarde, junto da experiência vêm a autonomia e o desenvolvimento da capacidade de mudar um planejamento, caso necessário, o que não nega a importância do ato de planejar.

Ao longo do estágio eu percebia com mais facilidade o que era melhor ou não fazer em determinados momentos e não ficava mais tão presa ao plano de aula. Havia flexibilidade de minha parte, de modo que eu considerava isso nas aulas, o que foi possível graças à minha experiência e desenvolvimento enquanto professora. Diante das surpresas e dos desafios, eram necessários "improvisos", a partir dos quais aprendia a ter mais segurança e a tomar decisões.

Nesse sentido, Russel (2005) traz Zeiger (1996) para dar dicas sobre gestão de sala de aula, incluindo desde a necessidade de o professor se manter calmo e controlado, até a importância de tomar atitudes necessárias à manutenção da disciplina e mudar de direção quando for preciso.

As mudanças no planejamento se davam por aspectos diversos: porque não dispunha de algum material com o qual contava; porque percebia, ao entrar em sala de aula, que as crianças estavam agitadas demais naquele dia e que, portanto, seria melhor não realizar determinada atividade ou adaptá-la; porque, ao iniciar uma atividade, percebia que seria melhor, por diversos motivos, realizá-la de outra forma, dentre outros fatores.

Hentschke e Del Ben (2003) defendem a mudança no planejamento, em determinado casos, e afirmam que

É preciso ter em mente que, embora o plano oriente a ação de ensinar, definindo um caminho para sua realização, isso não significa que essa ação possa ser determinada previamente em todos os seus detalhes. Isso ocorre porque o ensino é uma atividade complexa, que envolve várias pessoas, várias coisas a fazer simultaneamente e, por isso, sempre terá algum grau 
de imprevisibilidade, já que não é possível prever como os alunos, individualmente ou em grupo, estarão interagindo com os acontecimentos da sala de aula e com o contexto da prática. Por isso o plano poderá (e, em alguns casos, deverá) ser transformado, recriado e até mesmo abandonado e substituído durante a sua implantação (HENTSCHKE; DEL BEN, 2003, p. 178).

O trecho abaixo exemplifica uma mudança que fiz no planejamento para uma aula no Infantil I. Isso aconteceu, porque eu senti nos alunos sua inquietação e percebi que tomar outro rumo seria a melhor escolha para aquele momento.

Perguntei aos bebês quem sabia mandar beijos, mostrando como deveriam fazer. Comecei a cantar "Bom Dia", mas percebi que seria melhor repetir a canção por menos vezes, em vez de cantar para cada um falando seu nome, como planejado, pois os alunos estavam inquietos, então, eu queria distribuir logo os instrumentos (Diário de Campo, 2015, Aula 5, Infantil I).

O planejamento das aulas era importante, mas não determinava o que deveria ser feito e eu já tinha condições de "improvisar", se necessário, mas sempre com responsabilidade, ou seja, isso não significa que eu propunha quaisquer atividades para meus alunos, mas que escolhia prosseguir da melhor forma possível, para cada momento.

\section{AFINAL, O QUE É SER PROFESSORA DE MÚSICA NA EDUCAÇÃO INFANTIL?}

Como deve ser a aula de música na Educação Infantil? Como deve ser o professor? Ao longo do estágio descobri que a aula de música não é apenas música, mas que o professor precisa ter um olhar para além de sua disciplina, compreendendo que outras habilidades podem e devem ser desenvolvidas a partir dela, bem como da sala de aula, importando-se com a formação de seus alunos. Indo nessa direção, Garcia (2005) acredita que "é necessário que cada professor se sinta responsável pela formação global de seu aluno e não por um único aspecto, informativo e relacionado à sua área específica de atuação" (GARCIA, 2005, p. 8). 
Minha compreensão sobre o que é aula de música e, de modo mais abrangente, sobre o que é ser professora, se modificou e tornou-se mais ampla, a partir da experiência de estágio. Passei a compreender melhor meu papel, enquanto professora, de comprometer-me com a educação e com a formação global de meus alunos.

A partir disso, enxergava não só música em minhas aulas, mas também o desenvolvimento de outras habilidades a partir desse conteúdo, bem como dava atenção a isso, considerando sua importância.

Alguns bebês queriam receber logo seu instrumento, estavam ansiosos e a professora dizia: “Espera, Lucas... Espera!". “Uma criança tão pequena já está aprendendo que deve esperar sua vez, que deve ser paciente", pensei. Acho que a aula de música também pode ser isso, pode educar também nesse sentido e não preciso (nem devo!) poupar o aluno de aprender isso, só porque ainda é um bebê, como eu pensava antes (Diário de Campo, 2015, Aula 5, Infantil I).

Eu fiquei pensando se seria errado dizer que deveriam esperar seus instrumentos sem se levantar, com a condição de não os receberem se não obedecessem, mas decidi que não era errado, afinal, são crianças pequenas, mas na aula de música também haverá regras (Diário de Campo, 2015, Aula 1, Infantil III).

O comportamento também é aprendido na aula de música e, apesar de poder parecer óbvio, vivenciar isso na prática, junto dos alunos, significa desenvolver-se, saber educar, ser professora e conhecer crianças.

A partir do desenvolvimento de habilidades aparentemente externas à música (lembrando que não o são), a criança também pode conquistar mais desempenho nas aulas, uma vez que tudo está interligado. Nesse sentido, aprender a guardar os próprios brinquedos, por exemplo, é um exercício importante para a criança pequena.

Os bebês seguravam algumas cartilhas com imagens de animais, que havíamos usado na atividade, e eu pedi a eles que me devolvessem para guardarmos. Eles devolviam, não resistem mais e sabem o momento de guardar as cartilhas, as bolinhas e os instrumentos. 
Também sabem o momento de tocar e de ouvir em diversas situações (Diário de Campo, 2015, Aula 5, Infantil I).

Diante de determinadas situações, eu aprendia a lidar com as crianças e a tomar decisões em relação às suas atitudes.

Um aluno que não gostou do instrumento que recebeu, o arremessou para longe. Eu disse que não podemos jogar nossos instrumentos e o fiz pegá-lo novamente, agradecendo e dizendo que poderíamos trocá-lo, mas que ele nunca deveria jogá-lo. Ele pareceu entender e sentou-se em seu lugar, depois de trocar de instrumento, guardando o anterior na caixa (Diário de Campo, 2015, Aula 3, Infantil III).

Ser professora também é corrigir um comportamento de uma criança da forma correta, é importar-se com sua formação, de um modo geral, e isso se aprende com a prática. Da mesma forma, também na aula de música o aluno pode e deve aprender sobre comportamento.

Em sala de aula nos deparamos com situações com as quais podemos não estar preparados para lidar. Isso pode acontecer por não termos estudado o assunto na graduação, por exemplo, e, além disso, ainda que tenhamos estudado, a teoria apenas se reforça com vivência e experiência, portanto, é a prática que vai oportunizar ao professor o aprendizado.

Quando perguntei a uma menina por que ela não queria sua bolinha, ela respondeu que azul é cor de menino e eu disse que não existem cores de menino e cores de menina, que são apenas cores e que eu ficaria com a bolinha azul, mesmo sendo menina. A auxiliar Rafaela me ajudou e disse que sua calça era azul, mesmo ela sendo menina, e que azul era uma cor linda. A criança compreendeu e ficou com a bolinha azul, e eu fiquei feliz por ter conseguido aquilo (Diário de Campo, 2015, Aula 3, Infantil III).

No trecho acima, a aluna demonstra separar gênero por cores, o que, a meu ver, não é correto, portanto, procurei desfazer essa compreensão equivocada da criança, pois me senti responsável por corrigi-la (e de fato eu era), afinal eu sou professora de música, mas formo pessoas e pessoas não são formadas apenas de música. 


\section{LIDANDO COM A INSEGURANÇA}

Durante o estágio algumas dificuldades pessoais saltaram na prática docente, dentre elas a insegurança ou a falta de autoconfiança. Minha insegurança atrapalhava meu desenvolvimento em sala, o andamento das aulas, a condução das atividades, o enfrentamento de obstáculos e relacionamentos.

Eu não estava tão segura quanto na aula passada e acho que é porque a pedagoga (Elaine) não estava na sala. Além disso, o humor dos bebês nesse horário é diferente, sendo que parecem mais dispostos logo depois do horário da fruta, e menos chorosos. Quando eu acho que uma atividade não está dando certo, assim como eu esperava, fico com vergonha e com receio de as professoras estarem pensando mal da aula. Eu fico aflita e insegura (Diário de Campo, 2015, Aula 5, Infantil I).

Minha insegurança aumentava devido ao fato de perceber que uma das auxiliares da turma manifestava um certo desdém da aula de música. No decorrer das aulas, Maria sorria ironicamente ao perceber que eu e as demais estagiárias não conseguíamos acalmar os bebês, quando começavam a chorar, e logo, que o andamento da aula de música era prejudicado.

A auxiliar normalmente não se dispunha a ajudar de nenhuma maneira, nem ao menos pegando um deles no colo ou, até mesmo, permanecendo na sala até o fim da aula de música, para que se sentissem seguros com a presença de alguém conhecido. Em outros momentos, se negava a ajudar, ainda que eu pedisse, alegando que estaria ocupada com outros afazeres. O comportamento de Maria me atingia. Suas expressões despertavam em mim inseguranças e eu me sentia como uma intrusa, num ambiente estranho.

Fora os momentos em que os bebês choravam, acho que foi nessa atividade que Maria mais fez cara de desprezo, e eu observava muito isso, me incomodava e fui perdendo cada vez mais a vontade de estar ali, de dar aquela aula. Eu estava me sentindo muito mal e bastante desmotivada, tanto por seus olhares, quanto pelos choros e por não saber o que fazer em relação àquilo tudo (Diário de Campo, 2015, Aula 8, Infantil I). 
Diante da situação, eu me sentia desconfortável e a presença da auxiliar me desestabilizava, o que atrapalhava o andamento das aulas. Minhas inseguranças não eram relacionadas apenas ao comportamento das professoras, mas também ao desenvolvimento das aulas, sendo que precisava estar sempre com o planejamento por perto. Mais tarde isso deixou de ser um problema.

Além de estar insegura por conta da desaprovação constante de Maria, eu também não estava segura com o planejamento e precisava ficar com ele por perto para não esquecer qual era a próxima atividade, mas isso porque não estava confortável na aula e aí tudo fica mais difícil. Também temia que as atividades acabassem logo e sobrasse tempo da aula, mas isso nunca acontece (Diário de Campo, 2015, Aula 8, Infantil I).

Aos poucos, a partir das orientações e de reflexões, comecei a entender que talvez Maria não compreendesse o trabalho com música, não enxergasse sua importância e não soubesse dos objetivos. A partir do momento em que comecei a me mostrar mais confiante, certa daquilo que estava fazendo e administrando em mim as expressões e comentários que me desagradavam, a auxiliar passou a participar das aulas de música, ajudando no desenvolvimento das atividades com os bebês. Assim, perguntava a mim e às colegas de estágio sobre conteúdos e objetivos das atividades desenvolvidas.

Eu estava pensando em não entrar no Infantil I hoje, já que estávamos atrasadas, e quando pensava na aula dando errado, por causa de vários fatores, tinha ainda menos vontade de ir. Mas as meninas me disseram que dava tempo, que não estávamos muito atrasadas e eu me lembrei da promessa que havia feito a mim mesma: dar a minha aula, confiar em mim e ignorar "as caras e bocas" da auxiliar que sempre fazia isso. Entrei convicta na sala. Ouvimos uma música e paramos na porta para observar do que se tratava. Lá estavam, no colchão grande, vários bebês, a pedagoga e as auxiliares. [...] O clima na sala já era outro, [...] pela confiança que eu estava me obrigando a ter de que tudo daria certo e por lembrar que isso dependia, sobretudo, de mim (Diário de Campo, 2015, Aula 9, Infantil I). 
Tanto o trabalho em grupo, quanto as orientações e a reflexão foram fundamentais para que eu pudesse mudar aquele quadro. Passei a me sentir mais segura por não estar sozinha nas aulas e, além disso, a partir das discussões com a orientadora, refletia e buscava por alternativas que me ajudavam.

\section{ALGUMAS CONQUISTAS}

As auxiliares de Educação Infantil do CMEI mudaram bastante em relação a mim e às aulas, ao longo do primeiro semestre. Elas ajudavam, se necessário, passaram a ser colegas de trabalho e a valorizar o estágio e a música na vida dos bebês, o que percebi a partir de modos de agir e de perguntas delas, demonstrando interesse por compreender a aula de música.

Cantávamos "O Caracol", durante a atividade, quando a auxiliar Maria perguntou qual era nosso objetivo com ela: "Para que é essa atividade?...". Bruna logo explicou. Ela continuou com as perguntas e quis saber se fazíamos a mesma aula em todas as turmas, então, explicamos que não, que tínhamos diferentes planejamentos, mas que em todas as turmas são desenvolvidas atividades de apreciação e memória, além de outros conteúdos (Diário de Campo, 2015, Aula 13, Infantil I).

Explicamos à professora e às auxiliares que voltaríamos depois das férias, continuando o estágio na escola. Não sei se elas ficaram contentes por isso, mas acredito que sim, pois, ultimamente, parecem estar gostando mais de nossas aulas. A professora Elaine tem cantado com os bebês antes das aulas de música, além de ouvir músicas com eles no aparelho de som. Maria mostra interesse pelas aulas, participando com a outra auxiliar e com a professora da turma, e perguntando sobre nossos objetivos com as atividades, dentre outras coisas. Acredito que estamos conquistando espaço, respeito e compreensão, ainda que aos poucos (Diário de Campo, 2015, Aula 14, Infantil I).

Minha relação com Maria se modificou a partir de mudança de minha postura. Dessa forma, a mudança da auxiliar em relação a mim e às aulas foi drástica. Por conta das 
mudanças, também a maneira da professora e das auxiliares do Infantil I de ver a música na vida dos bebês passou a ser outra. Maria me pediu músicas infantis, disse que gostaria de tê-las, caso não houvesse mais aulas de música na escola, com o fim do estágio. Além disso, disse que gostaria de utilizar as músicas em outros momentos, fora de minhas aulas, o que sugere a mudança de sua concepção em relação à importância da música para os bebês.

Eu e as demais estagiárias nos tornamos colegas das professoras e parte da escola. Dessa forma, eu me sentia parte do $\mathrm{CMEI}$, de seu corpo docente, e me sentia livre para agir, sempre. As professoras passaram a ajudar, por vontade própria, e desenvolvemos, aos poucos, uma relação de amizade. Além disso, também a relação com os bebês foi uma conquista, de forma que me tornei sua professora.

Depois que Elaine começou a participar das aulas, isso fez diferença. Acho que os bebês se sentem mais seguros com a presença dela, mas acredito que se ela precisar sair da sala, a aula continuará tranquilamente, porque os bebês têm, agora, mais confiança em nós, uma vez que estamos com eles há um bom tempo e já nos familiarizamos (Diário de Campo, 2015, Aula 12, Infantil I).

Compreendi que Maria agia com indiferença e até mesmo desprezo em relação à aula de música, porque não compreendia o trabalho e eu não conseguia mudar isso por demonstrar insegurança.

Maria também tem participado das aulas de música, e ainda sorrindo! Ela e Elaine ficam com a gente o tempo todo, nos ajudam e estão sempre de bom humor. Elas, inclusive, cantam músicas infantis com os bebês e, às vezes, até "puxam" uma música em alguma atividade da aula de música, que tenha o mesmo assunto de que estamos falando. Estão realmente em sintonia conosco e com a aula (Diário de Campo, 2015, Aula 10, Infantil I).

Apesar de ter enfrentado problemas com algumas professoras no CMEl, tudo estava muito diferente alguns meses depois, quando mudei minha postura e deixei de me desestabilizar com algumas reações, confiante de que a professora de música era eu e que eu sabia o porquê e o valor de cada atividade que 
era desenvolvida com os bebês, independente do que estivessem pensando quaisquer pessoas. A partir de uma mudança em mim, do desenvolvimento de minha autoconfiança, as aulas começaram a melhorar.

Depois de quase um semestre de estágio meu comportamento em sala de aula e na vida já era outro. Diante de determinadas situações, eu sabia agir melhor do que no começo do ano, pois com segurança do que estava fazendo e certeza da importância de minha aula, tinha autonomia para tomar decisões.

Com a experiência de estágio, pude melhorar minhas ações, a partir de situações que me colocavam frente a obstáculos, exigindo de mim autoconfiança para lidar com esses, atenção para percebê-los, além de reflexão, amadurecimento e prática, para ter possibilidades de buscar por possíveis alternativas. Dessa forma, me desenvolvia, enquanto professora e ser humano, e melhorava meu desempenho em sala de aula.

Coisas que pareciam um problema, no início do estágio - tais como os choros dos bebês, minhas inseguranças e a relação com algumas auxiliares de Educação Infantil - já não representavam nada algum tempo depois, pois tratava-se de acontecimentos que me passavam despercebidos, uma vez que me utilizava de estratégias e os resolvia naturalmente.

Através da repetição, da experiência, das orientações, do passar do tempo e do desenvolvimento de minha maturidade enquanto professora, coisas que, a princípio, eram um problema ou uma necessidade, deixaram de sê-lo e tornaram-se pequenas. Apesar disso, ilustram bem meu desenvolvimento e, de modo que passaram a ser tão simples, cairiam no esquecimento não fossem os relatórios para me lembrar. Perceber erros e superar desafios são coisas que exigem tempo, pois trata-se de um processo.

Finalizando, a orientação e o acolhimento da escola foram fundamentais para que minha relação com a docência concretizasse uma experiência de formação efetiva, que modificou minha forma de ser e de estar no estágio e na vida. Dessa forma, a partir da contribuição de pessoas e de circunstâncias que estiveram a meu favor durante o trabalho, tenho dado meus primeiros passos em direção à docência em música. 


\section{CONSIDERAÇÕES FINAIS}

Neste trabalho tive por meta discutir meu processo de formação inicial como educadora musical, a partir de minha atuação no Estágio Supervisionado em música, desenvolvendo uma reflexão sobre meu desenvolvimento acadêmico, pedagógico e humano. Para isso, realizei catalogação dos relatórios de aula das turmas Infantil I e Infantil III, destacando trechos que evidenciavam reflexões sobre meu desenvolvimento como educadora musical, e, assim, lançando mão do referencial teórico-metodológico Memorial de Formação.

Acredito que a vida acadêmica seja parte da vida como um todo, não sendo possível separá-la das experiências em outros momentos e espaços. À medida que sou uma única pessoa, também minha vida é uma só, seja dentro ou fora da universidade, seja como professora ou como aluna. Dessa forma, tanto o CMEl, quanto a escola de música e as influências geradas pela história de vida familiar, escolar e universitária e pelas diversas interações pessoais vividas nos mais variados contextos, contribuíram para aprendizados comuns, complementando-se. Tenho tomado consciência disso com as orientações de estágio e, também, ao tecer esse trabalho.

Ter esse olhar, de não separar a vida dentro e fora da academia, foi fundamental para meu desenvolvimento, pois passei a relacionar o estágio a outras experiências, a cada momento, desenvolvendo minha prática enquanto professora. Sendo assim, estava sempre em constante reflexão sobre o estágio, sobre como melhorar minhas ações, mesmo estando fora do CMEl ou em momentos alheios àquele de pensar e escrever relatórios. Pelo fato de não poder separar a vida em dois ou mais momentos e espaços, descobri o Memorial de Formação, com o qual me identifiquei, visto que sempre escrevera memoriais, desde criança.

Este trabalho pode contribuir para o campo da educação musical no que diz respeito à reflexão sobre a formação docente, pois há um esforço para que a autenticidade de meu próprio crescimento como educadora musical fique 
traduzido em palavras, ou seja, a autenticidade do trabalho tem fundamentos na formação de professores, de forma que me coloco enquanto protagonista das mudanças de que depende meu desenvolvimento.

Além disso, o trabalho pode indicar que a pesquisa por professores em formação contribui para um maior desenvolvimento profissional, já que, dessa forma, é possível apropriar-se dos próprios saberes e aperfeiçoá-los, bem como perceber lacunas e refinar, assim, a compreensão quanto a tornar-se professora. A formação de profissionais reflexivos, perspectiva não apenas da área da educação musical, mas também de outras áreas, pode ter contribuição da escrita, que favorece o pensamento reflexivo, constituindo-se em valiosa ferramenta na formação do professor.

A escrita reflexiva possibilitou ganhos individuais, uma vez que pude, a partir dela, narrar minhas experiências, revelar ideias e refletir sobre o que fazia nesse trabalho. Dessa forma, incorporei uma postura reflexiva que poderá ser levada e mantida em minhas experiências docentes, indo para além da universidade e, até mesmo, do exercício profissional, levada para a vida em seus mais variados contextos e considerada nas relações e interações pessoais. Tanto a escola em que realizei o estágio, quanto diversos outros contextos interativos estimularam e problematizaram o desenvolvimento de saberes que permanecerão em constante transformação e aprimoramento. 


\section{REFERÊNCIAS}

BRUNER, Jerome. A cultura da educação. Porto Alegre. Artmed Editora, 2001.

GARCIA, Lenise Aparecida Martins Garcia. Competências e Habilidades: você sabe lidar com isso? Educação e Ciência On-line, Brasília: Universidade de Brasília. Disponível em: <http://www. cereja.org.br/pdf/20050112_competencias.pdf $>$. Acesso em: 20 de janeiro de 2016.

GOIS, Micheline Prais de Aguiar Marim; MALAGUTTI, Vânia Gizele. Música para bebês: do cotidiano para sala de aula. IV Encontro de Pesquisa em Música da Universidade Estadual de Maringá (EPEM) Maringá, 2009. Disponível em: $<$ http://www.dmu.uem.br/pesquisa/index.

HENTSCHKE, Liane; DEL BEN, Luciana. Aula de música: do planejamento e avaliação à prática educativa. In: . Ensino de música: propostas para pensar e agir em sala de aula. São Paulo: Moderna, 2003. p. 176-188.

LOURO, Ana Lúcia M.; TEIXEIRA, Ziliane L. O.; RAPÔSO, Mariane M. A "Narrativa de Si" como perspectiva para a reflexão do professor de música: abordagens do Grupo NarraMus. In: LOURO, Ana Lúcia M.; TEIXEIRA, Ziliane L. O.; RAPÔSO, Mariane M. (Org.). Aulas de música: narrativas de professores numa perspectiva (auto) biográfica. Curitiba, PR. Editora CRV, 2014.

MARQUES, Mario Osorio. Professores falantes de si na sala de aula, na escola e na constituição da pedagogia. In: OLIVEIRA, Valeska Fortes de (Org.). Imagens de Professor: significações do trabalho docente. Ijuí, RS. Editora Unijuí, 2004.

MARTINS, Camila. Música para bebês: um estudo do curso de extensão da UEM. Maringá, 2011. Trabalho de Conclusão de Curso (Graduação em Música Com Habilitação em Licenciatura em Educação Musical) - Universidade Estadual de Maringá.

MILLS, C. Wright, 1916-1962. Sobre o artesanato intelectual e outros ensaios/C. Wright Mills; seleção e introdução Celso Castro; tradução Maria Luiza X. de A. Borges; revisão técnica Celso Castro. Rio de Janeiro: Jorge Zahar Ed., 2009. 
PRADO, Guilherme; SOLIGO, Rosaura. Memorial de formação: quando as memórias narram a história da formação... In: PRADO, Guilherme; SOLIGO, Rosaura (Org.). Porque escrever é fazer história: revelações, subversões, superações. Campinas, SP: Graf, 2005. Disponível em: <https://www.fe.unicamp.br/ensino/graduacao/ downloads/proesf-memorial_GuilhermePrado_RosauraSoligo.pdf > . Acesso em: 20 de abril de 2018.

RUSSELL, Joan. Estrutura, conteúdo e andamento em uma aula de música na la série do ensino fundamental: um estudo de caso sobre gestão de sala de aula. Revista da ABEM, Porto Alegre, V. 12, 73-88, mar. 2005.

SANTOS, Gladys Rosana Barbosa dos. A Música na vida de crianças: de colheres de pau à internet. Maringá, 2011. Trabalho de Conclusão de Curso (Graduação em Música Com Habilitação em Licenciatura em Educação Musical) - Universidade Estadual de Maringá.

SANTOS, Suellen Assunção. Experiências narradas no ciberespaço: um olhar para as formas de se pensar e ser professora que ensina matemática. Dissertação de mestrado. Porto Alegre, 2009. Disponível em: $\quad$ http://www.lume.ufrgs.br/handle/10183/21385?locale=pt_ BR>. Acesso em: 20 de abril de 2018.

SARTORI, Adriane Teresinha. O memorial de formação e a graduação de (futuros) professores. SCRIPTA, Belo Horizonte, v. 15, n. 28, p. 267-284, 2011. Disponível em: $<$ http://periodicos.pucminas.br/index. php/scripta/article/view/4319/4466>. Acesso em: 20 de abril de 2018.

SEVERINO, Antonio Joaquim. Metodologia do Trabalho Científico. 20a Ed. São Paulo: Cortez, 1997, p. 141-143. Disponível em: <http:// educacao.uniso.br/pseletivo/proc_seletivo_2015/Doutorado/ memorial.pdf $>$. Acesso em: 20 de abril de 2018.

SUDAN, Daniela Cássia. Saberes em construção de uma professora que pesquisa a própria prática. Dissertação de Mestrado. São Carlos, 2005. Disponível em: <http://bdtd.ibict.br/vufind/Record/ SCAR_3df99d79c959850e8de44617da9f2ff4>. Acesso em: 20 de abril de 2018. 